\title{
DEPOSIÇÃO DA CALDA DE PULVERIZAÇÃO APLICADA COM PONTAS DE JATO PLANO EM DIFERENTES PARTES DA PLANTA DE SOJA (Glycine max) E MILHO (Zea mays)
}

\author{
Bruno Monteiro da Silva ${ }^{1}$, Renato Adriane Alves Ruas², Diego Sichocki ${ }^{3}$, Luciel Rauni Dezordi ${ }^{4}$, Leonardo Fideles \\ Caixeta $^{5}$
}

\section{RESUMO}

Objetivou-se com este trabalho, avaliar a influência de pontas hidráulicas sobre a deposição de calda em alvos posicionados em diferentes partes de plantas com arquiteturas distintas. Realizou-se experimento em esquema fatorial $2 \times 3 \times 3$, sendo duas culturas (soja e milho), três locais de deposição da calda nas plantas (terço superior, terço médio e terço inferior) e três pontas de pulverização (API 110-02, AD 110-02D e ADIA 110-02D), no delineamento de blocos casualizados com quatro repetições, totalizando 72 unidades experimentais. A análise de variância constatou efeito significativo na interação tríplice entre os fatores estudados. As pontas de pulverização que proporcionam gotas finas/médias (100-250 $\mu \mathrm{m})$ apresentam melhor deposição de calda nos diferentes terços das plantas de soja e milho, consequentemente maior cobertura do alvo. Todas as pontas utilizadas no trabalho proporcionam deposição de calda considerada satisfatória para a maioria das aplicações de agrotóxicos.

Palavras-chave: cobertura foliar, espectro de gotas, Glycine max, tecnologia de aplicação, Zea mays

\author{
ABSTRACT \\ DEPOSITION OF SPRAY SOLUTIONS APPLIED WITH JET PLANE SPRAY NOZZLES ON \\ DIFFERENT PARTS OF THE PLANTS OF SOYBEAN (Glycine max) AND CORN (Zea mays)
}

The objective of this study was to evaluate the influence of spray nozzles on solution deposition on targets positioned on different plant parts with distinct architectures. Experiments were conducted in a 2 x 3 x 3 randomized block design, consisting of two crops (corn and soybeans), three sites for deposition of the spray solution on plants the (upper third, middle third and bottom third) and three spray nozzles (API 110-02, AD 110-02D and ADIA 110-02D), with four replications, totaling 72 experimental units. The analysis of variance showed a significant effect on the triple interaction between the factors studied. The spray nozzles that produce fine droplets $(100-175 \mu \mathrm{m})$ indicated better deposition of the solution on the different portions of the soybean and corn plants, with consequent higher coverage of the target. All nozzles used in this study resulted in spray deposition considered satisfactory for most pesticide applications.

Keywords: leaf cover, droplet spectrum, Glycine max, application technology, Zea mays

Recebido para publicação em 15/12/2012. Aprovado em 12/06/2013.

1 - Graduando em Agronomia, UFV/Rio Paranaíba-MG, Brasil, bruno.monteiro@ufv.br

2 - Engenheiro Agrônomo, Professor Adjunto da UFV/Rio Paranaíba-MG, renatoruas@ufv.br

3 - Engenheiro Agrônomo, Mestrando em Produção Vegetal, UFV/Rio Paranaíba-MG, diegolns@yahoo.com.br

4 - Graduando em Agronomia, UFV/Rio Paranaíba-MG, luciel.dezordi@hotmail.com

5 - Graduando em Agronomia, UFV/Rio Paranaíba-MG, leonardo.caixeta@ufv.br 


\section{INTRODUÇÃO}

O objetivo da tecnologia de aplicação de agrotóxicos é colocar a quantidade certa de ingrediente ativo no alvo, com a máxima eficiência e da maneira mais econômica possível, afetando, o mínimo possível, o meio ambiente (MATTHEWS, 2002). Os cultivos da soja (Glycine max) e do milho (Zea mays) representam importantes atividades agrícolas no Brasil, fornecendo produtos largamente utilizados para alimentação humana, animal e matérias-primas para a indústria. Isso tem exigido da agricultura maior eficiência na produção desses grãos. Nesse contexto, o controle de pragas, doenças e plantas daninhas tornou-se uma preocupação constante do agricultor, pois, em geral, são realizadas várias aplicações de agrotóxicos nas lavouras durante o ciclo produtivo, onerando o custo de produção, aumentando o risco de contaminação de operadores e meio ambiente. Não raro, o elevado número de aplicações ocorre devido a falhas na tecnologia de aplicação utilizada. Esses problemas ocorrem, sobretudo, porque muitos técnicos e produtores preocupam-se apenas com o produto a ser utilizado, dispensando pouca atenção à tecnologia de aplicação (CUNHA; CARVALHO, 2005).

A eficácia de fitossanitários modernos é diminuída durante o processo de aplicação (HALL, 1993). Sabe-se que o uso da pulverização na agricultura depende não somente de produtos de ação comprovada, mas também da adequada tecnologia desenvolvida para sua aplicação (BALAN et al., 2005).

Cada cultura apresenta uma arquitetura foliar característica, que interfere na penetração das gotas no dossel vegetativo (BERNI et al., 1999). Assim sendo, é necessário realizar estudos específicos para determinar quais são as melhores características técnicas das pontas hidráulicas que permitem uma melhor deposição da calda em cada terço da planta (inferior, médio e superior), uma vez que o alvo biológico pode estar próximo ao solo, no dossel ou no terço médio das plantas. Desta forma, as pontas de pulverização, que são responsáveis por fragmentar e distribuir o líquido de forma uniforme sob a área, representam importante componente dos pulverizadores para proporcionar uma aplicação eficaz. Portanto, é indispensável o estudo dos parâmetros relacionados à população e espectro de gotas produzidas pelas pontas hidráulicas com indução de ar ou não, como o diâmetro da mediana volumétrica (DMV), coeficiente de homogeneidade $(\mathrm{CH})$, densidade de gotas (DEN), e porcentagem de cobertura do alvo (COB), a fim de se avaliar sua eficácia no controle de plantas que apresentem diferentes áreas foliares.

Atualmente, diversas características quanto à distribuição e espectro de gotas encontram-se disponíveis nos acessórios de pulverização que o mercado oferece, tais como, as pontas hidráulicas (BAUER et al., 2006), o que pode possibilitar pulverização eficiente em diferentes tipos de alvos a serem atingidos. A escolha da ponta de pulverização que possibilita a melhor deposição da calda na região da planta que representa o alvo biológico é essencial para a realização de um controle eficaz.

As avaliações da deposição de calda são empregadas nas pesquisas de tecnologia de aplicação, como instrumento para desenvolver e melhorar técnicas de aplicação de defensivos (PALLADINI, 2000). Dois fatores que afetam sobremaneira essa deposição são o tamanho e a anatomia das plantas (NORDBY, 1989). De maneira geral, a deposição é menor nas partes mais baixas e internas do dossel das culturas, sobretudo, devido ao efeito "guarda-chuva" proporcionado pelas partes mais altas de algumas espécies de plantas. Para os produtos com ação de contato, este efeito é maior. Sendo assim, torna-se de suma importância conhecer o perfil de penetração das gotas produzidas pelas pontas hidráulicas no dossel da lavoura, a fim de ultrapassar essa barreira e atingir também as partes mais baixas.

As gotas produzidas pelas pontas de pulverização com indução de ar sofrem menos interferência das condições meteorológicas, pelo fato de apresentarem diâmetros maiores que as gotas produzidas pelas pontas convencionais (BAUER et al., 2006), e assim, são menos susceptíveis a deriva (MATTHEWS, 1999). Elas também proporcionam boa cobertura do alvo em relação às demais pontas que pulverizam gotas grossas a muito grossas sem indução de ar, pois geram gotas que se deslocam até o alvo com menor velocidade, devido à elevada resistência causada pelo ar. Ao se chocarem sobre a superfície do alvo, resultam 
em espalhamento e retenção com características semelhantes às de gotas menores produzidas por pontas de pulverização convencionais (FAGGION; ANTUNIASSI, 2004).

A hipótese deste trabalho é que diferentes tipos de pontas podem proporcionar deposição de calda diferenciada nos terços da planta, a depender da sua arquitetura. Objetivou-se, portanto, avaliar a influência de diferentes tipos de pontas hidráulicas sobre a deposição de calda em alvos posicionados em diferentes partes de plantas com arquiteturas distintas.

\section{MATERIAL E MÉTODOS}

O experimento foi realizado em lavouras de soja e de milho, na área experimental da Coopadap (Cooperativa Agropecuária do Alto Paranaíba) e na fazenda Okuyama respectivamente, ambas no município de Rio Paranaíba-MG. Utilizamos o delineamento de blocos casualizados de forma que os tratamentos foram dispostos em esquema fatorial $2 \times 3 \times 3$, sendo duas culturas (soja e milho), três locais de deposição da calda nas plantas (terço superior, terço médio e terço inferior) e três pontas de pulverização (API 110-02, AD 110-02D e ADIA 110-02D), com quatro repetições, totalizando 72 unidades experimentais. As parcelas foram constituídas por cinco linhas, cada uma com 10 $\mathrm{m}$ de comprimento, sendo considerada como área útil somente as três linhas centrais, com exceção dos $0,50 \mathrm{~m}$ iniciais e finais. A implantação da cultura da soja (cultivar Valiosa) foi realizada com semeadura direta sobre a palha, no espaçamento de $0,50 \mathrm{~m}$ entre linhas. No momento da aplicação a soja encontrava-se no estádio fenológico R2 e a lavoura apresentava em média 9,2 plantas por metro. Já a cultura do milho (cultivar $30 \mathrm{~F} 53 \mathrm{H}$ ) foi estabelecida usando o preparo convencional do solo, com espaçamento de $0,70 \mathrm{~m}$ entre linhas. No momento da aplicação, o milho encontrava-se no estádio fenológico V6 e a lavoura apresentava em média 3,9 plantas por metro linear. Nesses estádios fenológicos concentra-se grande parte da aplicação de fungicidas/inseticidas em ambas as culturas.

Avaliou-se a deposição de calda em cada terço (superior, médio e inferior) das plantas de soja e milho, sendo o terço inferior próximo ao solo, o terço mediano em relação ao tamanho da planta e o dossel constituindo o terço superior. As pontas avaliadas foram: API 110-02 (jato plano), AD 11002D (jato plano duplo) e ADIA 110-02D (jato plano duplo com indução de ar). Segundo os fabricantes as duas primeiras pontas proporcionam gotas finas quando operam na pressão nominal, enquanto que a última produz gotas grossas.

A pulverização foi realizada com pulverizador costal pressurizado a $\mathrm{CO}_{2}$, equipado com barra de dois porta-bicos espaçados entre si a 0,50 m. A operação foi realizada com pressão de 300 $\mathrm{kPa}$ e a $0,50 \mathrm{~m}$ de altura em relação ao dossel. As condições climáticas foram monitoradas no momento das aplicações, sendo: temperatura média $25{ }^{\circ} \mathrm{C}$, umidade relativa $68 \%$ e velocidade do vento 7 a $8 \mathrm{~km} \mathrm{~h}^{-1}$, podendo ser consideradas adequadas para aplicação de agrotóxicos em nível de campo (MATUO, 1990).

Para avaliar a deposição de calda proporcionada pelas pontas de pulverização nos diferentes terços das plantas de soja e milho, foram posicionadas três etiquetas de papel hidrossensível (38 x 26 $\mathrm{mm}$ ) em cada terço das plantas para constituir as unidades experimentais. Após a pulverização, que foi realizada com água, as etiquetas de papel hidrossensível foram digitalizadas e as imagens processadas no software Image Tool 3.0, para obtenção da área de cada mancha formada pelas gotas depositadas nos alvos. As áreas das manchas foram processadas no software Microsoft Excel, para determinação do diâmetro da mediana volumétrica (DMV), densidade de gotas (DEN), percentagem de cobertura do alvo (COB) e coeficiente de homogeneidade $(\mathrm{CH})$.

Para avaliar o volume de calda depositado nos diferentes terços das plantas, realizou-se a aplicação de calda constituída por água deionizada e corante Alimentício Azul brilhante, catalogado internacionalmente pela Food, Drug \& Cosmetic como FD\&C Blue n.1 (CUNHA et al., 2006), na concentração de $1500 \mathrm{mg} \mathrm{L}^{-1}$, nas unidades experimentas. Após a aplicação, foram retirados ao acaso 10 segmentos de folhas com, aproximadamente, cinco centímetros de comprimento cada, em cada terço das plantas presentes nas parcelas, para constituir a unidade experimental para a análise da deposição de calda. Em seguida, eles foram lavados com $100 \mathrm{~mL}$ de água deionizada e o líquido resultante foi depositado 
em recipientes plásticos e armazenado em ambiente protegido do sol e de temperaturas altas para posterior determinação da concentração do corante, uma vez que, estes não apresentam degradação luminosa por um período de até 10 horas, segundo MARCHI et al. (2005). Após a lavagem, os segmentos de folhas foram fotografados e as imagens processadas no software AutoCad 2007 para determinação da área foliar amostrada.

Para determinar a concentração do corante Azul Brilhante na solução resultante da lavagem dos segmentos de folhas, utilizou-se um espectrofotômetro UV (Modelo: Evolution 300 UV - Visible Spectrophotometer). Para determinar o comprimento de onda visando realizar a leitura de absorbância das amostras, foi feita uma varredura para verificar o comprimento de máxima absorbância do corante alimentício Azul Brilhante, obtendo-se a onda de $625 \mathrm{~nm}$ como a de máxima absorbância. Para calibrar o aparelho, foi realizada a construção de uma curva padrão, que consiste na determinação da absorbância de soluções que apresentam concentrações conhecidas do corante. Para obter estas soluções, foram realizadas diluições da calda empregada na pulverização, que apresentava $1500 \mathrm{mg} \mathrm{L}^{-1}$ de corante.

Utilizou-se a equação de regressão da curva padrão para converter a absorbância em concentração do corante. A partir da concentração do corante na solução de lavagem, volume de água utilizado para lavar as folhas $(100 \mathrm{~mL})$, concentração da solução aplicada (1500 $\left.\mathrm{mg} \mathrm{L}^{-1}\right)$ e a área foliar dos segmentos, foi possível determinar a deposição de calda pela Equação 1, proposta por LIMBERGER (2006):

$$
D=\frac{10^{6} V^{*}[\text { solução }]}{A^{*}[\text { Calda }]}
$$

em que,

$\mathrm{D}=$ deposição de calda $\left(\mu \mathrm{L} \mathrm{cm}^{-2}\right)$;

$\mathrm{V}=$ volume de água utilizado para lavar as folhas $(\mathrm{L})$; [solução] = concentração do corante na solução de lavagem $\left(\mathrm{mg} \mathrm{L}^{-1}\right)$;

$\mathrm{A}=$ área foliar do segmento $\left(\mathrm{cm}^{2}\right)$;

[calda] = concentração do corante na calda de pulverização $\left(\mathrm{mg} \mathrm{L}^{-1}\right)$.
Os dados foram submetidos à análise de variância pelo teste $F$, utilizando-se o software SAEG 9.1 e, quando significativas, as interações foram desdobradas entre os fatores estudados (cultura, pontas de pulverização e locais de deposição) e as médias comparadas pelo teste de Tukey, a $5 \%$ de probabilidade.

\section{RESULTADOS E DISCUSSÃO}

A análise de variância constatou efeito significativo nas interações duplas entre os fatores estudados: cultura $\mathrm{x}$ ponta, cultura $\mathrm{x}$ local de deposição e ponta $x$ local de deposição, procedendose, portanto, o desdobramento das mesmas. A ponta API 110-02 diferiu-se estatisticamente das demais quanto ao índice de cobertura do alvo, proporcionando maior cobertura na cultura do milho em relação à soja (Quadro 1). Isso comprova que a arquitetura da planta e o espectro de gotas produzido pela ponta influenciam na penetração das gotas no dossel das plantas, e, consequentemente, na deposição sobre os alvos biológicos. TAYLOR e SHAW (1993) afirmam que a arquitetura das plantas pode influenciar na deposição da calda pulverizada. COSTA (2005), por sua vez, cita que algumas espécies conseguem repelir a gota de aplicação em função de aspectos anatômicos na superfície foliar.

A deposição de calda proporcionada pelas pontas API 110-02 e ADIA 110-02D apresentaram diferença significativa na avaliação das culturas, sendo maior na cultura do milho (Quadro 1). Apesar da utilização de gotas finas, ou seja, gotas que apresentam 100-175 $\mu \mathrm{m}$ (ASABE, 2004) poder propiciar melhores coberturas e deposições, dependendo das condições climáticas e orientação da ponta de pulverização, elas devem ser empregadas com cautela sob pena de provocar deriva (MATTHEWS, 1992; ABI SAAB 1996).

Em relação às culturas e aos terços de deposição, nota-seque a cobertura dos diferentes locais de avaliação nas plantas de soja apresentou diferença estatística, enquanto que na cultura do milho, o terço inferior foi o único que apresentou diferença. Esse fato pode ser justificado pela maior densidade e pela arquitetura das folhas que as plantas de soja apresentam em relação às plantas de milho, o que dificulta o processo de penetração no dossel pelas gotas produzidas. 
Quadro 1. Deposição de calda, diâmetro da mediana volumétrica, densidade de gotas e percentagem de cobertura do alvo obtido pela pulverização com diferentes pontas hidráulicas na cultura da soja e do milho.

\begin{tabular}{|c|c|c|c|c|c|c|c|c|}
\hline \multirow[b]{3}{*}{ Pontas } & \multicolumn{8}{|c|}{ Culturas } \\
\hline & \multicolumn{4}{|c|}{ Soja } & \multicolumn{4}{|c|}{ Milho } \\
\hline & $\operatorname{DEP} P^{(1)}$ & $\mathbf{D M V}^{(2)}$ & $\operatorname{DEN}^{(3)}$ & $\mathrm{COB}^{(4)}$ & $\mathbf{D E P} \mathbf{P}^{(1)}$ & $\mathbf{D M V} \mathbf{V}^{(2)}$ & $\operatorname{DEN}^{(3)}$ & $\mathrm{COB}^{(4)}$ \\
\hline API 110-02 & $1,2 \mathrm{Ab}$ & $548,3 \mathrm{Bb}$ & $123,5 \mathrm{Aa}$ & $16,8 \mathrm{Ab}$ & $2,0 \mathrm{Ba}$ & $709,5 \mathrm{Aa}$ & $57,7 \mathrm{Ab}$ & $20,6 \mathrm{Aa}$ \\
\hline AD 110-02D & $1,4 \mathrm{Aa}$ & $556,1 \mathrm{Bb}$ & $72,1 \mathrm{Ba}$ & $18,7 \mathrm{Aa}$ & $3,1 \mathrm{Aa}$ & $741,2 \mathrm{Aa}$ & $39,4 \mathrm{Ab}$ & $16,2 \mathrm{Ba}$ \\
\hline ADIA $110-02 \mathrm{D}$ & $1,2 \mathrm{Ab}$ & $926,7 \mathrm{Aa}$ & $27,3 \mathrm{Ca}$ & $12,3 \mathrm{Ba}$ & $3,2 \mathrm{Aa}$ & $776,8 \mathrm{Ab}$ & $19,2 \mathrm{Ba}$ & $11,3 \mathrm{Ca}$ \\
\hline $\mathrm{CV} \%$ & 22 & 16,8 & 17,56 & 20,8 & 22,1 & 16,6 & 23,21 & 18,77 \\
\hline
\end{tabular}

A maior cobertura, tanto nas plantas de soja quanto nas plantas de milho, foi na posição superior da planta, ocasionada pela maior exposição do alvo à calda de pulverização, sendo que a cultura da soja, por questões anatômicas, apresentou cobertura significativamente maior na parte superior do que as plantas de milho. A menor cobertura foi verificada nos terços inferiores das plantas de soja e milho, sendo que, a cultura do milho obteve maior cobertura nessa posição em relação à cultura da soja, diferindo-se significativamente. Isso está relacionado ao maior volume foliar da posição superior da planta de soja, o que dificulta a penetração das gotas, interferindo no número de gotas nas posições inferiores, consequentemente na cobertura desse alvo. Esse fato também foi verificado por SILVA et al. (1997). Os autores verificaram que há sensível declínio na densidade de gotas depositadas nas posições inferiores do algodoeiro, quando se utilizam diferentes pontas de pulverização e pressões de trabalho. GAZZIERO et al. (2006), estudando a deposição de calda em soja transgênica, obtiveram maior retenção de glyphosate na parte aérea da planta, sendo o mesmo descrito por TOMAZELLA (1997), ao utilizar Brachiaria plantaginea.

A interação pontas hidráulicas e terços de plantas de soja e milho, evidenciada no Quadro 3 , demonstra que as pontas de jato plano sem indução de ar (API 110-02 e AD 110-02D), proporcionaram maior cobertura do terço superior, em relação a ponta com indução de ar (ADIA 11002D). Da mesma forma, as pontas jato plano sem indução de ar apresentaram significativamente maior cobertura no terço inferior. De forma semelhante, SCUDELER et al. (2004), avaliando a deposição promovida por gotas finas e por gotas muito grossas, pulverizadas por diferentes pontas, também não encontraram diferença de deposição na parte superior do dossel. Já na parte inferior das plantas, a ponta de jato plano promoveu maior cobertura das folhas. Provavelmente, isso ocorreu em virtude de suas gotas serem de menor tamanho em relação às produzidas pelas outras pontas. É esperado que, em geral, pontas que produzem gotas de menor tamanho promovam maior cobertura do alvo, principalmente quando a velocidade do vento é baixa. Esse resultado concorda com os dados apresentados por ANTUNIASSI et al. (2004). Os autores, avaliando a cobertura de folhas de soja com diferentes pontas de pulverização, concluíram que as gotas finas $(100-175 \mu \mathrm{m})$ propiciam melhores coberturas nas posições média e baixa das plantas. Nesse contexto, CUNHA et al. (2010), avaliando diferentes pontas de pulverização em diferentes posições na lavoura de milho encontrou influência na deposição de gotas na parte superior do dossel entre duas pontas distintas (TTI 110-02 e TTJ 110-02). Além desses fatores, a concentração da 
Quadro 2. Coeficiente de homogeneidade, densidade de gotas e percentagem de cobertura do alvo obtido nos diferentes terços na cultura da soja e do milho.

\begin{tabular}{|c|c|c|c|c|c|c|}
\hline \multirow[b]{3}{*}{ Terços } & \multicolumn{6}{|c|}{ Culturas } \\
\hline & \multicolumn{3}{|c|}{ Soja } & \multicolumn{3}{|c|}{ Milho } \\
\hline & $\mathbf{C H}^{(1)}$ & $\operatorname{DEN}^{(2)}$ & $\mathrm{COB}^{(3)}$ & $\mathbf{C} \mathbf{H}^{(1)}$ & $\operatorname{DEN}^{(2)}$ & $\mathrm{COB}^{(3)}$ \\
\hline Superior & $9,3 \mathrm{Aa}$ & $68,5 \mathrm{Ba}$ & $23,9 \mathrm{Aa}$ & $6,29 \mathrm{Ab}$ & $27,1 \mathrm{Ab}$ & $20,0 \mathrm{Ab}$ \\
\hline Médio & $4,3 \mathrm{Ba}$ & $108,5 \mathrm{Aa}$ & $17,2 \mathrm{Ba}$ & $3,6 \mathrm{Bb}$ & $46,3 \mathrm{Ab}$ & $17,5 \mathrm{Aa}$ \\
\hline Inferior & $2,4 \mathrm{Ca}$ & $45,9 \mathrm{Ca}$ & $6,7 \mathrm{Cb}$ & $2,2 \mathrm{Ca}$ & $42,9 \mathrm{Aa}$ & $10,6 \mathrm{Ba}$ \\
\hline CV \% & 11,3 & 23,2 & 21,9 & 14,9 & 17,2 & 21,8 \\
\hline
\end{tabular}

${ }^{(1)}$ Coeficiente de homogeneidade; (2)Densidade de gotas $\left(\right.$ gotas $\left.\mathrm{cm}^{-2}\right)$; ${ }^{(3)}$ Percentagem de cobertura (\%). Médias que possuem letras maiúsculas iguais na coluna e minúsculas nas linhas não diferem entre si pelo teste de Tukey $(\mathrm{p}<0,05)$.

Quadro 3. Deposição de calda, densidade de gotas e percentagem de cobertura do alvo obtido pela pulverização com diferentes pontas hidráulicas nos diferentes terços na cultura da soja e do milho.

\begin{tabular}{|c|c|c|c|c|c|c|c|c|c|}
\hline \multirow[b]{3}{*}{ Terços } & \multicolumn{9}{|c|}{ Pontas } \\
\hline & \multicolumn{3}{|c|}{ API 110-02 } & \multicolumn{3}{|c|}{ AD 110-02D } & \multicolumn{3}{|c|}{ ADIA $110-02 D$} \\
\hline & $\mathbf{D E P} P^{(1)}$ & $\operatorname{DEN}^{(2)}$ & $\mathrm{COB}^{(3)}$ & $\operatorname{DEP} P^{(1)}$ & $\operatorname{DEN}^{(2)}$ & $\mathrm{COB}^{(3)}$ & $\mathbf{D E P} \mathbf{P}^{(1)}$ & $\operatorname{DEN}(2)$ & $\mathrm{COB}^{(3)}$ \\
\hline Superior & $1,9 \mathrm{Ab}$ & $49,4 \mathrm{Cab}$ & $23,2 \mathrm{Aa}$ & $3,0 \mathrm{Aa}$ & $67,2 \mathrm{Aa}$ & $26,4 \mathrm{Aa}$ & $3,4 \mathrm{Aa}$ & $26,8 \mathrm{Ab}$ & $16,3 \mathrm{Ab}$ \\
\hline Médio & $1,7 \mathrm{Aa}$ & $143,9 \mathrm{Aa}$ & $21,9 \mathrm{Aa}$ & $2,1 \mathrm{Ba}$ & $62,9 \mathrm{ABb}$ & $15,9 \mathrm{Bb}$ & $2,1 \mathrm{Ba}$ & $25,4 \mathrm{Ac}$ & $14,2 \mathrm{Ab}$ \\
\hline Inferior & $1,1 \mathrm{Bb}$ & $78,5 \mathrm{Ba}$ & $11,1 \mathrm{Ba}$ & $1,6 \mathrm{Ca}$ & $37,1 \mathrm{Bb}$ & $10,0 \mathrm{Ca}$ & $1,3 \mathrm{Cab}$ & $17,6 \mathrm{Ab}$ & $5,0 \mathrm{Bb}$ \\
\hline $\mathrm{CV} \%$ & 24,9 & 23,8 & 18,8 & 14,8 & 21,3 & 21,6 & 15 & 24,2 & 19,3 \\
\hline
\end{tabular}

(1)Deposição de calda $\left(\mu \mathrm{L} \mathrm{cm}^{-2}\right)$; ${ }^{(2)}$ Densidade de gotas (gotas $\left.\mathrm{cm}^{-2}\right)$; ${ }^{(3)}$ Percentagem de cobertura (\%). Médias que possuem letras maiúsculas iguais na coluna e minúsculas nas linhas não diferem entre si pelo teste de Tukey $(\mathrm{p}<0,05)$.

calda pulverizada no terço mais baixo da planta pode ser considerada alta quando comparada com o trabalho feito por CUNHA et al. (2006), onde os autores, avaliando deposição de calda ao longo do dossel da lavoura de soja, encontraram valores médios de $0,231 \mu \mathrm{L} \mathrm{cm}^{-2}$ para diferentes tipos de pontas avaliadas.

Tomados em conjunto, esses resultados evidenciam que as pontas de pulverização, responsáveis pela fragmentação do líquido em gotas, por distribuí-las na área e controlar a vazão, devem ser criteriosamente selecionadas para cada operação, dependendo da cultura trabalhada e do local onde o alvo biológico se encontra e pretendese atingir.

\section{CONCLUSÕES}

- A cultura do milho apresenta uma percentagem de cobertura do alvo maior nas três posições avaliadas em relação à cultura da soja;

- As pontas de pulverização que proporcionam gotas de 100-250 $\mu \mathrm{m}$ apresentam melhor deposição de calda nos diferentes terços das plantas de soja e milho, consequentemente maior cobertura do alvo.

\section{REFERÊNCIAS BIBLIOGRÁFICAS}

ABI SAAB, O.J.G. Avaliação de um sistema de 
aplicação de defensivos utilizado em videiras no Município de Londrina/PR. 1996. 65p. Tese (Mestrado em Agronomia) - Faculdade de Ciências Agronômicas, Universidade Estadual Paulista, Botucatu, 1996.

ANTUNIASSI, U.R.; CAMARGO, T.V.; BONELLI, A.P.O.; ROMAGNOLE, H.W.C. Avaliação da cobertura de folhas de soja em aplicações terrestres com diferentes tipos de pontas. In: SIMPÓSIO INTERNACIONAL DE TECNOLOGIA DE APLICAÇÃO DE AGROTÓXICOS, 3., 2004, Botucatu, SP. Anais... Botucatu: FEPAF, 2004. p.48-51.

ASABE. Calibration and Distribution Pattern Testing of Agricultural Aerial Application Equipment (ASAE S386.2). American Society of Agricultural and Biological Engineers. St. Joseph, 2004.

BALAN, M.G.; ABI SAAB, O.J.G.; FONSECA, I.C.B.; SILVA, C.G.; SASAKI, E.H. Pulverização em alvos artificiais: avaliação com o uso do software conta-gotas. Ciência Rural, Santa Maria, v.35, n.4, p.916-919, 2005.

BAUER, F.C.; RAETANO, C.G.; PEREIRA, F.A.R. Padrões de distribuição volumétrica de pontas de pulverização de jato plano 11002 , com e sem indução de ar, sob diferentes espaçamentos e alturas. Engenharia Agrícola, Jaboticabal, v.26, n.2, p.546-551, 2006.

BERNI, R.F.; MACHADO, V.O.F.; COSTA, G.R.; BARATA, G.; PAULA, R.S. Avaliação da cobertura de gotas provocada por diferentes bicos de pulverização na cultura do milho e do feijão. Pesquisa Agropecuária Tropical, Goiânia, v.29, n.1, p.49-52, 1999.

COSTA, N.C.; MARTINS, D.; RODELLA, R.A.; COSTA, L.D.N.C. Deposição de gotas de pulverização e $\mathrm{pH}$ foliar no controle de plantas daninhas aquáticas. Scientia Agrícola, Piracicaba, v.62, n.3, p.227-234, 2005.

CUNHA, J.P.A.; CARVALHO, W.P.A.
Distribuição volumétrica de aplicações aéreas de agrotóxicos utilizando adjuvantes. Engenharia na Agricultura, Viçosa, v.13, n.2, p.130-135, 2005.

CUNHA, J.P.A.R.; REIS, E.F.; SANTOS, R.O. Controle químico da ferrugem asiática da soja em função de ponta de pulverização e de volume de calda. Ciência Rural, Santa Maria, v.36, n.5, p.1360-1366, 2006.

CUNHA, J.P.A.R; SILVA, L.L.S. Aplicação aérea e terrestre de fungicida para o controle de doenças do milho. Ciência Agronômica, Fortaleza, v.41, n.3, p.366-372, 2010.

FAGGION, F.; ANTUNIASSI, U.R. Ar na aplicação. Cultivar Máquinas, Pelotas, Ano IV, n.26, p.12-15, 2003-2004.

GAZZIERO, D.L.P.; MACIEL, C.D.G.; SOUZA, R.T.; VELINI, E.D.; PRETE, C.E.C.; OLIVEIRA NETO, W. Deposição de glyphosate aplicado para o controle de plantas daninhas em soja transgênica. Planta Daninha, Viçosa, v.24, n.1, p.173-181, 2006.

HALL, F.R. Application to plantation crops. In: MATTHEWS, G.A.; HISLOP, E.C. Application techonology for crop protection. Wallingford: CAB, 1993. p.187-213.

LIMBERGER, A.R. Avaliação da deposição da calda de pulverização em função do tipo de ponta e do volume aplicado na cultura do feijão. 2006. 51p. Tese (Mestrado em Agronomia) - Universidade Estadual do Oeste do Paraná, Campus de Marechal Cândido Rondon, Marechal Cândido Rondon, 2006.

MARCHI, S.R.; MARTINS, D.; COSTA, N.V.; TERRA, M.A.; NEGRISOLI, E. Degradação luminosa e retenção foliar dos corantes azul brilhante FDC-1 e amarelo tartrasina FDC-5 utilizados como traçadores em pulverizações. Planta Daninha, Viçosa, v.23, n.2, p.287-294, 2005.

MATTHEWS, G.A. The application of chemicals for plant disease control. In: WALLER, J.M.; 
LENNÉ, J.M.; WALLER, S.J. Plant pathologist's pocketbook. London: $\mathrm{CAB}, 2002$. p.345-353.

MATTHEWS, G.A. Application of pesticides to crops. Imperial College Press, London. 1999. 325p.

MATTHEWS, G.A. Pesticide application methods. 2. ed. London: Longman, 1992. 405p.

MATUO, T. Técnica de aplicação de defensivos agrícolas. Jaboticabal: Funep, 1990. 139p.

NORDBY, A. Application and control of the distribution of plant nutrients and pesticides. IN: DODD \& GRACE (ed.) Land and water use. Roterdam: balkema, 1989. p.273-279.

PALLADINI, L.A. Metodologia para avaliação da deposição em pulverizações. 2000. 111p. Tese (Doutorado em Agronomia) - Faculdade de Ciências Agronômicas, Universidade Estadual Paulista, Botucatu, 2000.

SCUDELER, F.; BAUER, F.C.; RAETANO, C.G. Ângulo da barra e ponta de pulverização na deposição da pulverização em soja. In: SIMPÓSIO INTERNACIONAL DE TECNOLOGIA DE APLICAÇÃO DE AGROTÓXICOS, 3., 2004, Botucatu, SP. Anais... Botucatu: FEPAF, 2004. p.13-16.

SILVA, O.R.R.F da; MARQUES, L.; CARVALHO, O.S.; VIEIRA, R. de M. Avaliação do depósito de gotas obtidos através da pulverização eletrostática e da convencional sobre a cultura do algodoeiro. Revista Brasileira de Engenharia Agrícola Ambiental, Campina Grande, v.1, n.2, p.101-105, 1997.

TAYLOR, W.A.; SHAW, G.B. The effect of drop speed, size and surfactant on the deposition of spray on barley and radish or must ard. Pesticide Science, v.14, n.6, p.659-65, 1993.

TOMAZELLA, M.S. Avaliação da deposição da calda de pulverização em função da densidade populacional de Brachiaria plantaginea, volume e ângulo de aplicação. 1997. 78f. Tese (Mestrado em Agronomia) - Universidade Estadual Paulista Júlio de Mesquita Filho, Botucatu, 1997. 